\title{
The molecular characterization of new types of $S$. cerevisiae x S. kudriavzevii hybrid yeasts unveils a high genetic diversity
}

\begin{tabular}{|r|l|}
\hline Journal: & Yeast \\
\hline Manuscript ID: & YEA-Jun-11-0053.R1 \\
\hline Wiley - Manuscript type: & Research Article \\
\hline Date Submitted by the & n/a \\
\hline Complete List of Authors: & $\begin{array}{l}\text { Peris, David; Universitat de València, Inst. Cavanilles de Biodiversitat } \\
\text { i Biologia Evolutiva } \\
\text { Belloch, Carmela; CSIC, Universitat de Valencia, Departamento de } \\
\text { Biotecnologia de Alimentos, Instituto de Agroquimica y Technologia } \\
\text { de Alimentos } \\
\text { Lopandić, Ksenija; University of Natural Resources and Applied Life } \\
\text { Sciences, Viena, Institute of Applied Microbiology } \\
\text { Álvarez-Pérez, José; Universidad de León, Instituto de Investigación } \\
\text { de la Viña y el Vino, Campus de Ponferrada } \\
\text { Querol, Amparo; CSIC, Universitat de Valencia, Departamento de } \\
\text { Biotecnologia de Alimentos, Instituto de Agroquimica y Technologia } \\
\text { de Alimentos } \\
\text { Barrio, Eladio; Universitat de València, Inst. Cavanilles de } \\
\text { Biodiversitat i Biologia Evolutiva }\end{array}$ \\
\hline Keywords: & \begin{tabular}{l} 
Saccharomyces \\
\hline
\end{tabular} \\
\hline \hline
\end{tabular}

\section{SCHOLARONE ${ }^{\text {Tw }}$ Manuscripts}


1 The molecular characterization of new types of S. cerevisiae $\times \mathbf{S}$.

2 kudriavzevii hybrid yeasts unveils a high genetic diversity.

3

4 David Peris ${ }^{1}$, Carmela Belloch ${ }^{2}$, Ksenja Lopandić ${ }^{4}$, José Manuel Álvarez-

5 Pérez $^{3}$, Amparo Querol $^{2}$ and Eladio Barrio ${ }^{1}$

6

$7 \quad{ }^{1}$ Institute Cavanilles of Biodiversity and Evolutionary Biology, University of

8 Valencia, Valencia, Spain.

$9{ }^{2}$ Department of Biotecnology, Institute of Agrochemistry and Food Technology

10 (CSIC), Valencia, Spain.

$11{ }^{3}$ Vine and Wine Research Institute, University of León, 24400-Ponferrada,

12 Spain

$13{ }^{4}$ Austrian Center of Biological Resources and Applied Mycology, Institute of

14 Applied Microbiology, University of Natural Resources and Applied Life

15 Sciences, Muthgasse 18, 1190 Vienna, Austria.

16

17 Corresponding author:

18 Dr. Eladio Barrio

19 Institut 'Cavanilles' de Biodiversitat i Biologia Evolutiva

20 Universitat de València

21 P.O. Box 22085

22 E- 46071 València

23 SPAIN

24 Tel.: +34 963543667

25 Fax: +34 963543670

26 E-mail: eladio.barrio@uv.es

27 Running Title: A high genetic diversity among S. cerevisiae x S. kudriavzevii

28 hybrids

29 Keywords: Saccharomyces hybrids, S. cerevisiae, S. kudriavzevii, wine,

30 dietary, clinical yeasts. 


\section{Abstract}

32 New double and triple hybrid Saccharomyces yeasts were characterized by using PCR-restriction fragment length polymorphism of 35 nuclear genes, located at different chromosome arms, and the sequencing of one nuclear and one mitochondrial genes. Most of these new hybrids were originally isolated from fermentations, however, two of them correspond to clinical and dietary supplement isolates. This is the first time that the presence of double hybrids $S$. cerevisiae $x$ S. kudriavzevii in non-fermentative substrates is reported and

39 investigated.

40 The phylogenetic analysis of the MET6 nuclear gene confirmed the double or

41 triple parental origin of the new hybrids. The restriction analysis of gene regions

42 in these hybrids revealed a high diversity of genome types. From these

43 molecular characterizations, a reduction of the S. kudriavzevii fraction of the

44 hybrid genomes is observed in most hybrids.

45 Mitochondrial inheritance in hybrids was deduced from the analysis of the

46 mitochondrial COX2 gene sequences, which showed that most hybrids received

47 the mitochondrial genome from the $S$. kudriavzevii parent. However, two strains

48 inherited a $S$. cerevisiae COX2, being the first report of $S$. cerevisiae $\times S$.

49 kudriavzevii hybrids with S. cerevisiae mitochondrial genomes. These two

50 strains are those showing a higher $S$. kudriavzevii nuclear genome reduction,

51 especially in the wine hybrid $\mathrm{AMH}$. This may be due to the release of selective

52 pressures acting on the other hybrids to maintain kudriavzevii mitochondria-

53 interacting genes. 


\section{Introduction}

The genus Saccharomyces consists of eight species, three of them associated with industrial fermentation processes ( $S$. bayanus, $S$. cerevisiae, and S. pastorianus), and five isolated from natural habitats (S. arboriculus, $S$.

cariocanus, S. kudriavzevii, S. mikatae and S. paradoxus) (Kurtzman 2003;

60 Wang and Bai 2008). S. cerevisiae, the predominant species responsible for the

61 alcohol fermentation, has been found associated to diverse fermentation processes including baking, brewing, distilling, wine making, cider production, etc. and also in different traditional fermented beverages and foods around the world. The species $S$. bayanus includes two recognized varieties, bayanus and uvarum (Vaughan-Martini and Martini 2011). S. bayanus var. uvarum is present in wine and cider fermentations from cold regions of Europe (as examples see

67 Naumov et al. 2001; Demuyter et al. 2004). The S. pastorianus taxon includes hybrid strains between $S$. bayanus and $S$. cerevisiae, which are responsible for

69 the production of lager beer (Kodama et al. 2005). The rest of the species are

70 only associated with natural habitats, with the exception of some S. paradoxus strains isolated from Croatian vineyards (Redzepović et al. 2002), that show a

72 good winemaking performance (Orlić et al. 2010).

During their evolution, yeasts have suffered diverse selective processes to

74 become adapted to the fermentation conditions (Querol et al. 2003). Diverse

75 molecular mechanisms were involved in the generation of the evolutionary novelties that allowed the adaptation of yeasts to the fermentation processes

77 (for a review see Barrio et al. 2006). In the case of the genus Saccharomyces, one of the most interesting mechanisms involved in their adaptation to industrial 
79 processes, is the generation of interspecific hybrids (Querol and Bond 2009).

80 Hybrids between $S$. cerevisiae and $S$. bayanus were already identified several

81 decades ago (for a review see Kodama et al. 2005). In the last years, a new

82 type of hybrids, between S. cerevisiae $\times$ S. kudriavzevii, have been found both

83 in winemaking and brewing (Bradbury et al. 2006; González et al. 2006, 2008;

84 Lopandić et al. 2007).

85 In the present study we characterize the genome composition of new $S$.

86 cerevisiae $\times$ S. kudriavzevii hybrids. These new hybrids include two strains

87 isolated from wine regions located in the southernmost limits of the Oceanic and

88 Continental Europe, and two hybrids isolated for the first time from non-

89 fermentative sources, such as a human respiratory tract isolate (deLlanos et al.

90 2004) and a strain employed as dietary supplement. Other hybrids, molecularly

91 characterized for the first time in this study, are some commercial wine strains

92 described as such by Bradbury et al. (2006) and some of the Austrian wine

93 hybrids (Lopandić et al. 2007), as well as two triple hybrids S. bayanus x S.

94 cerevisiae x S. kudriavzevii CID1 (Groth et al. 1999) and CBS2834 (González et

95 al. 2006). The genetic characterization was performed by restriction analysis of

9635 nuclear genes located in different chromosomes, and by sequencing the

97 nuclear gene MET6 and the mitochondrial COX2 genes. Accordingly, these new

98 hybrids were compared to those characterized in our previous study (González

99 et al. 2008).

100

101 Materials and methods

102

103 Yeast strains and culture media 
104 The natural yeast hybrids S. cerevisiae $\times$ S. kudriavzevii used in this 105 study were originally isolated from different sources and locations as described 106 in Table 1. Yeast strains were grown at $28^{\circ} \mathrm{C}$ in GPY medium (2\% glucose, $107 \quad 0.5 \%$ peptone, $0.5 \%$ yeast extract).

$109 P C R$ amplification and restriction analysis of 35 nuclear gene regions

110 Characterization of the hybrids was performed by PCR amplification and

111 restriction of 35 gene regions located in different chromosome arms (Fig. 2).

112 DNA was extracted following the procedure described by Querol et al. (1992).

113 Amplification and digestion of the nuclear genes was performed by using the

114 methodology described in González et al. (2008) except for the subtelomeric

115 MNT2 gene, that failed to amplify the $S$. kudriavzevii gene and, hence, it was

116 replaced by GCN1. Primers used for amplification of GCN1 gene were GCN1-5

117 (GGTTTRGTKAAAGGTTAYGG) and GCN1-3' (CACCAGCYAAAATRGTTGG)

118 and PCR conditions were as in González et al. (2008), but using an annealing

119 temperature of $55.5^{\circ} \mathrm{C}$.

120

121 Amplification, sequencing and phylogenetic analysis of COX2 and MET6 genes The genes COX2 and MET6 were amplified by PCR using the primers

123 and conditions described in Belloch et al. (2000) and González et al. (2006),

124 respectively. PCR products were cleaned with the Perfectprep Gel Cleanup kit

125 (Eppendorf, Hamburg, Germany) and both strands of the DNA were directly 126 sequenced using the BigDyeTM Terminator V3.0 Cycle Sequencing Kit (Applied

127 Biosystems, Warrington, UK), following the manufacturer's instructions, in an 
128 Applied Biosystems automatic DNA sequencer Model ABI 3730l (Life

129 Technologies Coorporation, Carlsbad, California).

130 COX2 and MET6 sequences obtained for the present study are listed in

131 Table 1 with their accession numbers. Other sequences from hybrids were

132 retrieved from sequence databases (accession numbers for MET6 sequences

133 AJ973280-AJ973295 and AJ973305-AJ973322; and for COX2 sequences

134 AJ938037-AJ93844, AJ938047, AJ938048 and AJ966727-AJ966733).

135 Finally, MET6 sequences from reference or type strains of $S$. bayanus

136 var. uvarum (MCYC 623), S. cerevisiae (S288C), S. kudriavzevii (IFO 1802 ${ }^{\top}$ ), S.

137 mikatae (IFO $1815^{\top}$ ) and S. paradoxus (CECT $1939^{\mathrm{NT}}$ ) were retrieved from the

138 fungal alignment viewer of the Saccharomyces Genome Database

139 (http://db.yeastgenome.org/cgi-bin/FUNGl/showAlign).

140 Each set of homologous sequences was aligned in MEGA 4 (Tamura et

141 al. 2007). The sequence evolution model that fits our sequence data best was

142 optimized using the corrected Akaike Information Criterion (AICc) with a BioNJ

143 tree as the initial tree, implemented in jModelTest program (Posada 2008). The

144 best fitting model of evolution for MET6 sequences was TIM1 model (Posada

145 2003) with a gamma distribution $(G)$ of substitution rates with a shape

146 parameter $\alpha=0.35$; and for COX2 gene sequences the TVM model (Posada

147 2003) with a gamma distribution $(G)$ of substitution rates with a shape

148 parameter $\alpha=0.123$ and $46.2 \%$ of invariable sites (I). The parameters of each

149 model, estimated in the previous analysis, were used to obtain the best trees

150 under optimality criterion of maximum-likelihood (ML). Tree reliability was

151 assessed using non-parametric bootstrap re-sampling of 1000 pseudo- 
152 replicates. Phylogenetic analyses were performed using PhyML 3.0 program

153 (Guindon et al. 2010).

154 In the case of COX2 sequences, due to evidences of recombination

155 obtained from sequence comparisons, a Neighbor-net network analysis was

156 also performed with SPLITSTREE4 program (Huson and Bryant 2006).

157

158 Results

159 Analysis of the hybrid nature of the strains by the phylogenetic analysis of

160 MET6 gene sequences.

161 To confirm the hybrid nature of the strains under study and their

162 genealogical relationships, we performed phylogenetic analyses of partial

163 sequences of a nuclear (MET6) and a mitochondrial (COX2) genes, because

164 such sequences are also available for other hybrids (González et al. 2006,

165 2008).

166 Three different MET6 sequence types were found in hybrids that

167 correspond to those of the reference strains of the parental species $S$. bayanus,

168 S. cerevisiae and S. kudriavzevii (Fig. 1). Thus, the average number of

169 nucleotide subtitutions among $S$. cerevisiae alleles is $0.97 \pm 0.88$ (from 0 to 3

170 differences), among $S$. kudriavzevii alleles is $0.23 \pm 0.59$ (from 0 to 3 ) and

171 among $S$. bayanus var. uvarum is $0 \pm 0$. In contrast, average numbers of

172 nucleotide differences between species are $83.89 \pm 0.78$ (S. cerevisiae vs. $S$.

173 kudriavzevii alleles, 83 to 87 nucleotide differences), $66.78 \pm 0.84$ (S. bayanus

174 var. uvarum vs. S. cerevisiae alleles, 65-68 differences) and 60.11 \pm 0.42 (S.

175 bayanus var. uvarum vs. S. kudriavzevii alleles, 60-62). 
176 All double and triple hybrids included in the analysis contain two or three

177 MET6 alleles coming from their parental species ( $\mathrm{B}, \mathrm{C}$ and $\mathrm{K})$, except double

178 hybrids HA1841 and AMH that lost the S. kudriavzevii MET6 allele. These

179 results confirm the hybrid nature of the new strains.

180

181 Nuclear genome characterization of Saccharomyces hybrids

182 The restriction patterns of the 35 genes for the differentiation of the $S$.

183 cerevisiae and S. kudriavzevii alleles were described in González et al. (2008)

184 with the exception of MNT2 which was replaced in the present study by GCN1.

185 The restriction analysis of the GCN1 gene region yielded the following

186 fragments: Haell, S. cerevisiae $462+302+144+114$ bp, and S. kudriavzevii

$187450+366+206$ bp; Mspl, S. cerevisiae $514+508$ bp, and S. kudriavzevii 1022

188 bp; and Cfol, S. cerevisiae $766+256$ bp, and S. kudriavzevii $634+388$ bp.

189 Hybrids characterized in a previous study (González et al. , 2008) were also

190 assayed for this gene, resulting in the presence of both parental copies in all of

191 them.

192 The PCR-RFLP patterns of the 10 newly characterized S. cerevisiae $\times$ S.

193 kudriavzevi hybrids, and the 2 triple hybrids are depicted in Figures 2 and 3,

194 respectively. The specific alleles present in each hybrid strain are given in the

195 Supplementary Table S1 and the new restriction patterns in Supplementary

196 Table S2.

197 Since the S. cerevisiae and S. kudriavzevii genomes are colineal (Kellis et

198 al. 2003), the locations of the gene regions under analysis were chosen to

199 obtain information about the presence of possible chromosomal

200 rearrangements in the hybrid genomes, as described in other hybrids (González 
201 et al. 2008; Belloch et al. 2009). This way, the absence in the hybrids of $S$.

202 kudriavzevii alleles for genes located in the same chromosome likely resulted

203 from the loss of the whole chromosome. However, the loss of one gene located

204 in a chromosome but not the other genes of the same chromosome can be

205 postulated as a result of recombination between homeologous chromosomes,

206 as demonstrated for some hybrids (Belloch et al., 2009). This resulted in the

207 replacement of the missing segment by the homologous segment from the other

208 chromosome of different parental origin (see Figures 2 and 3).

209 This way, chromosomal rearrangements can be postulated as occurred in

210 chromosomes IV (AMH), V (IF6), VII (AMH, VIN7, IF6 and MR25), IX (IF6,

211 MR25), X (IF6, MR25), XI (PB7 and IF6), XIII (IF6, MR25), XIV (MR25), XV

212 (AMH) and XVI (IF6). In four wine hybrids (SOY3, from Croatia, and HA 1835,

213 HA 1837 and HA 1842 from Austria) no rearrangement can be deduced

214 because they contain both parental alleles for all genes.

215 In general, the $S$. cerevisiae genome fraction is maintained in all these

216 double hybrids whereas a progressive loss of the S. kudriavzevii genes is

217 observed. This reduction is more evident in the case of hybrid AMH, which has

218 lost most of the S. kudriavzevii chromosomes.

219 In the case of the triple hybrids (Fig. 3), the typical restriction pattern of $S$.

220 bayanus var. uvarum was found in addition to those of $S$. cerevisiae and $S$.

221 kudriavzevii alleles, indicating that they contain chromosomes from the three

222 parental species. The S. cerevisiae and S. kudriavzevii chromosomes are co-

223 lineal (synthenic), however, the chromosomes of $S$. bayanus var. uvarum

224 contain 4 differential reciprocal translocations (Kellis et al. 2003), as depicted in 
225 Figure 3. In the case of triple hybrids, a higher preservation of the S. bayanus

226 var. uvarum fraction is observed.

227 The comparison of the RFLP patterns obtained in this study for the new

228 hybrids and those described by González et al. (2008, see their figure 3)

229 reveals a considerable diversity in the genome structure of $S$. cerevisiae $\times$ S.

230 kudriavzevii hybrids, although certain similarities among strains are observed as

231 well. Accordingly, double hybrid strains can be classified in three groups

232 according to the parental genome rearrangements. The first group includes

233 hybrids that maintain the complete genome from both parents (most HA strains

234 and SOY3) or have independently lost from 1-2 chromosomes or chromosome

235 regions from S. kudriavzevii (wine strains PB7, VIN7 and most brewing hybrids),

236 the second group comprises strains with a moderate loss (3-4) of $S$.

237 kudriavzevii chromosomes or chromosome regions, including 3 shared events

238 (Swiss wine hybrids and the brewing strain CECT 11003), and the third group

239 includes strains with moderate (MR25, 6 losses) to large S. kudriavzevii gene

240 losses (CECT 11002, IF6 and AMH, with 9, 11 and 13, respectively).

\section{Mitochondrial inheritance in hybrids}

The analysis of mitochondrial COX2 gene sequences has been shown as

244 useful to decipher which parental species contributed with their mitochondria to

245 the hybrid strains (González et al. 2006).

246 The comparative analysis of COX2 sequences with those previously

247 described (González et al. 2006), showed the presence of new haplotypes in

248 hybrids PB7, AMH and IF6 (Fig. 2 and 3). The wine hybrids AMH and IF6

249 contain COX2 sequences more related to S. cerevisiae (1 and 14 differences, 
250 respectively being the first description of $S$. cerevisiae $\times$ S. kudriavzevii hybrids

251 that received their mitochondrial genomes from a S. cerevisiae parent.

252 The other new hybrids contain COX2 sequences that correspond to

253 previously described haplotypes. Thus, with the exception of PB7, all new wine

254 hybrids contain haplotype K4, already described in the triple hybrid CBS 2834.

255 This haplotype is closely related to haplotypes K2 and K3 from Swiss wine

256 hybrids ( 1 and 2 nucleotide differences, respectively) and haplotypes exhibited

257 by the Japanese type (haplotype K1, 5 differences) and European strains from

258 S. kudriavzevii (haplotypes K8 and 9, with 1 and 3 differences, respectively).

259 The clinical isolate MR25 exhibits the same haplotype K6 described in brewing

260 hybrids, which is related to haplotype K10 present in the wine hybrid PB7 (6

261 nucleotide differences).

262 However, a detailed analysis of the COX2 sequence alignment suggested

263 the possibility of reticulate evolution due to recombination (Table 2). This way,

264 haplotypes K5 (triple hybrid CID1), K6 (brewing hybrids CECT 1388, 1990,

26511002,11011 and the clinical strain MR25) and K10 (wine hybrid PB7) appear

266 as putative recombinant sequences with similarities to $S$. kudriavzevii, $S$.

267 cerevisiae and S. paradoxus sequences in their 5'-end, central and 3'-end

268 regions, respectively (see Table 2 ).

269 In the case of reticulate evolution due to recombination, a better

270 representation of the phylogenetic relationships is obtained by a Neighbor-net

271 network analysis (Figure 4). Most wine hybrids (except PB7 and AMH) and two

272 Trappist beer hybrids (CECT 11003 and 11004) inherited their mitochondrial

273 genomes (haplotypes K2, K3 and K4) from S. kudriavzevii, AMH and IF6

274 received their mitochondrial genomes from S. cerevisiae, although IF6 COX2 
275 appears in a striking intermediate position between S. cerevisiae and $S$.

paradoxus-S.mikatae clades, likely due to its highly divergent 3' end. Finally,

277 most brewing hybrids and the clinical isolate (haplotype K6), the cider CID1 (K5)

278 and the wine PB7 (K10) hybrids appear in an intermediate position due to their

279 chimerical COX2 sequences.

280

281

Different groups of hybrids according to their nuclear and mitochondrial

282

genome constitutions

The combined analysis of the nuclear and mitochondrial genome

compositions of $S$. kudriavzevii double and triple hybrids indicates a higher

285

genetic diversity. Strains that differed in a few chromosomal rearrangements

286

contain different mitochondrial haplotypes (e.g. PB7 and the Austrian and

287 Croatian hybrids) and others showing important chromosomal differences share

the same mitochondrial sequences (e.g. MR25 and brewing hybrids).

In other cases, there is a certain association between the nuclear and

290 mitochondrial diversities. This way, the two hybrids with a S. cerevisiae

291 mitochondrial DNA are those that lost a higher fraction of S. kudriavzevii nuclear

292 genome. As well, with the mentioned exception of PB7, wine hybrids appear in

293 two closely related clusters, the Austrian-Croatian cluster (also including VIN7)

294 with low number of chromosomal rearrangements and the sharing the same $S$.

295 kudriavzevii-like mitochondrial haplotype K4, and the Swiss cluster (also

296 including Trappist hybrids CECT11003 and 11004), which share several fixed

297 rearrangements (Belloch et al. 2009) and the S. kudriavzevii-like mitochondrial

298 haplotype K2 (including the derived K3). 
299 In the case of the two triple hybrids known so far, they also show important

300 differences both in their mitochondrial and nuclear genomes. Thus, these

301 strains do not share any common chromosomal rearrangements indicating

302 independent losses in the three fractions of their hybrid genomes. Moreover, the

303 wine triple hybrid inherited a S. kudriavzevii mitochondrial genome similar to

304 that present in wine double hybrids, whilst the cider hybrid contains a

305 mitochondrial COX2 closely related to that present in most brewing, the clinical

306 and a wine hybrid with similarities intermediate between $S$. cerevisiae and $S$.

307 kudriavzevii.

308

309 Discussion

310 New strains expanding the distribution range of Saccharomyces kudriavzevii

311 hybrids

312 It is more than a decade since an unusual $S$. bayanus $\times$ S. cerevisiae

313 hybrid, CID1, isolated from home-made Breton cider, was identified as bearing

314 a mitochondrial genome coming from S. kudriavzevii (Masneuf et al. 1998;

315 Groth et al. 1999). Later, a S. kudriavzevii contribution to a fraction of the

316 chimerical nuclear genome of this strain was demonstrated (Naumova et al.

317 2005; González et al. 2006).

318 Some years later, a new type of natural hybrid strains between $S$.

319 cerevisiae $\times$ S. kudriavzevii was described in wine fermentations (Bradbury et

320 al., 2006; González et al., 2006; Lopandić et al., 2007). and brewing

321 environments (González et al., 2008).

322 In the present study, new S. cerevisae x S. kudriavzevii hybrid yeasts are

323 described and molecularly characterized. These hybrids contribute to expand 
324 the geographical distribution range of this type of hybrids as well as the sources

325 whence they can be isolated.

326 This way, the new wine hybrids (PB7 and SO3) were isolated from wine

327 fermentation in the southernmost locations where this kind of hybrids has been

328 isolated so far (Pajares de los Oteros, in Northwestern Spain, and Daruvar, in

329 Central Croatia, respectively). These new descriptions extend the distribution

330 limits of $S$. cerevisiae $\times$ S. kudriavzevii hybrids to the Southern limit of the

331 European wine regions of Oceanic and Continental climate, where these

332 hybrids have been found so far associated to fermentation processes. In these

333 wine regions, hybrids can be predominant (Schütz and Gafner 1994; González

334 et al. 2006; Lopandić et al. 2007) likely due to a better adaptation to lower

335 temperatures compared to S. cerevisiae (González et al. 2007).

336 The molecular characterization of PB7 showed that, although its nuclear

337 genome composition is similar to other wine hybrids, exhibits a recombinant

338 mitochondrial genome different but closely related to brewing hybrids. Its

339 marginal distribution and its peculiar genome characteristics are indicative of a

340 putative independent origin from other wine hybrids. However, the genome

341 composition of the Croatian SOY3 hybrid was identical to Austrian hybrids,

342 predominant in another wine region of the same Pannonian basin (Lopandić et

343 al. 2007), with similar climatologic characteristics as well as historical links in

344 the development of viticulture and enology.

345 In these Southern locations where the new wine hybrids were isolated,

346 hybrids did not appear as predominant. In both cases, these wine hybrids were

347 found at low frequencies and coexisting with the dominant $S$. cerevisiae strains

348 during the first stages of the wine fermentations. Perhaps the milder 
349 temperatures at which spontaneous fermentations occur in these Southern

350 regions still allow $S$. cerevisiae to outcompete these hybrids.

$351 \quad$ The present study also describes for the first time $S$. cerevisiae $x$ S.

352 kudriavzevii hybrids isolated from non-fermentative environments. Strain MR25

353 is a human respiratory isolate from 'Hospital del Vall d'Hebron', Barcelona,

354 Spain; and IF6, is commercialized as a dietary supplement. These hybrids are

355 quite different at the genome level, particularly in their mitochondrial genomes.

356 The clinical isolate MR25 shares a COX2 sequence identical to that present in 4

357 brewing hybrids, indicating that beer could likely be the source of infection, and

358 the dietary supplement IF6 exhibits a S. cerevisiae mitochondrial DNA.

360 The high genetic diversity among Saccharomyces kudriavzevii hybrids suggests independent hybridization origins

362 The analysis of the nuclear and mitochondrial genome compositions of $S$.

363 kudriavzevii double and triple hybrids unveiled a high diversity, which likely is

364 indicative of independent primary, as well as secondary, hybridization events.

365 The fact that hybrids inherited 3 types of mitochondrial genomes $(S$.

366 cerevisiae-like, S. kudriavzevii-like and recombinant) from their parental

367 ancestors is indicative of at least 3 different origins. Moreover, the important

368 differences in their nuclear genome compositions could also be taken as

369 evidences of independent primary hybridization events.

370 The presence of recombinant mitochondrial genomes in hybrids can be

371 explained by recombination events occurring after the fusion of mitochondria

372 observed in conjugating Saccharomyces spores or cells. This kind of

373 recombination events were already described in S. cerevisiae at the within- 
374 species level (Berger and Yaffe 2000), but this is the first time that is described

375 in hybrids at the between-species level. However, we suspect that these

376 recombination events are limited to this COX2 region because sequences from

377 the next downstream gene, COX3, correspond to S. kudriavzevii (data not

378 shown).

379 In addition, the existence of natural triple $S$. bayanus var. uvarum $\mathrm{S}$.

380 cerevisiae $\times$ S. kudriavzevii hybrids can be explained by secondary

381 hybridization between either $S$. cerevisiae x S. kudriavzevii hybrids with $S$.

382 bayanus var. uvarum strains or $S$. bayanus var. uvarum $x$ S. cerevisiae hybrids

383 with S. kudriavzevii strains. Although both types of double hybrids have been

384 found associated to fermentation environments, the first type of secondary

385 hybridization event could be more probable because $S$. kudriavzevii seems to

386 be present only in natural environments (Sampaio and Gonçalves 2008; Lopes

387 et al. 2010) and is outcompeted by S. cerevisae in experimental wine

388 fermentations (Arroyo-López et al. 2011), whilst S. bayanus var. uvarum

389 coexists with, or even replaces, S. cerevisiae in wine fermentations from cold

390 regions of Europe (Torriani et al. 1999; Naumov et al. 2000; 2002; Rementería

391 et al. 2003; Demuyter et al. 2004). However, a secondary hybridization event in

392 natural environments, involving a $S$. kudriavzevii and a $S$. bayanus $\times$ S.

393 cerevisiae, cannot be totally discarded.

394 After hybridization, the hybrid genome suffers random genomic

395 rearrangements mediated by crossing-over between homeologous

396 chromosomes (Belloch et al. 2009). If these rearrangements were randomly

397 fixed, hybrids with a higher number of rearrangements should derive from older

398 hybridization events, and hybrids with no rearrangements should be very 
399 recent. However, double hybrids showed a trend to maintain the S. cerevisiae

400 genome and to reduce the $S$. kudriavzevii that can only be explained by

401 selection acting under the strong restrictive conditions prevailing during

402 fermentation (nutrient depletion, osmotic stress, fermenting temperature,

403 increasing levels of ethanol, etc.). The better adaptation of $S$. cerevisiae to

404 these prevailing conditions constrains the loss of the S. cerevisiae fraction of

405 the hybrid genome, and only the S. kudriavzevii genome fraction of selective

406 importance for the hybrid (e.g. involved in adaptation to low fermentation

407 temperatures) would be maintained. The fact that hybrids with a S. kudriavzevii

408 mitochondrial genome maintain a larger fraction of the S.kudriavzevii genome

409 than hybrids with a S. cerevisiae mitochondrial DNA, such as AMH and IF6, is

410 also indicative that the inheritance of a S. kudriavzevii mitochondrial genome

411 constrains to maintain those S. kudriavzevii genes involved in the proper

412 function and maintenance of the mitochondria. Incompatibility between nuclear

413 and mitochondrial genes has been reported for artificial S. cerevisiae $\times$ S.

414 bayanus hybrids (Lee et al. 2008). Accordingly, strains possessing $S$.

415 cerevisiae-inherited mitochondria overcome this restriction and may lose these

416 S. kudriavzevii mitochondrial-related genes from their nuclear genome.

418 Acknowledgements

419 We thank Helmut Gangl, Rosa de Llanos, Silvia LLopis, Sandi Orlić, 420 Lallemand Bio and Anchor Wine Yeasts for providing yeast strains. This work 421 was supported by Spanish Government projects AGL2009-12673-CO2-01 and 422 AGL2009-12673-CO2-02 to AQ and EB, respectively, and Generalitat 423 Valenciana (project PROMETEO/2009/019) to AQ, EB and CB. DP and JMA-P 
424 acknowledge to the Spanish Government for their FPI (Ministerio de Ciencia e

425 Innovación) and FPU (Ministerio de Educación) fellowships, respectively.

426

427

428

429

430

431

432

433

\section{References}

Arroyo-López FN, Pérez-Través L, Querol A, Barrio E. 2011. Exclusion of Saccharomyces kudriavzevii from a wine model system mediated by Saccharomyces cerevisiae. Yeast 28: 423-435.

Barrio E, González SS, Arias A, Belloch C, Querol A. 2006. Molecular mechanisms involved in the adaptive evolution of industrial yeasts. In Yeasts in Food and Beverages, Querol A, Fleet GH (eds). Springer-Verlag, Berlin; 153-174.

Belloch C, Querol A, García MD, Barrio E. 2000. Phylogeny of the genus Kluyveromyces inferred from mitochondrial cytochrome-c oxidase II gene. Int J Syst Evol Microbiol 50: 405-416.

Belloch C, Pérez-Torrado R, González SS, Pérez-Ortín JE, García-Martínez J, Querol A, Barrio E. 2009. Chimeric genomes of natural hybrids of Saccharomyces cerevisiae and Saccharomyces kudriavzevii. Appl Environ Microbiol 75: 25342544.

Berger KH, Yaffe MP. 2000. Mitochondrial DNA inheritance in Saccharomyces cerevisiae. Trends Microbiol 8: 508-513.

444 Bradbury J, Richards K, Niederer H, Lee S, Rod Dunbar P, Gardner R. 2006. A 445 homozygous diploid subset of commercial wine yeast strains. Antonie van $446 \quad$ Leeuwenhoek 89: 27-37.

447 deLlanos R, Querol A, Planes AM, Fernández-Espinar MT. 2004. Molecular $448 \quad$ characterization of clinical Saccharomyces cerevisiae isolates and their 449 associaton with non-clinical strains. Syst Appl Microbiol 27: 427-435. 
450 Demuyter C, Lollier M, Legras JL, Le Jeune C. 2004. Predominance of Saccharomyces

451 uvarum during spontaneous alcoholic fermentation, for three consecutive years,

452 in an Alsatian winery. J Appl Microbio/ 97: 1140-1148.

453 González SS, Barrio E, Gafner J, Querol A. 2006. Natural hybrids from Saccharomyces fermentations. FEMS Yeast Res 6: 1221-1234.

González SS, Barrio E, Querol A. 2008. Molecular characterization of new natural hybrids between Saccharomyces cerevisiae and Saccharomyces kudriavzevii from brewing. Appl Environ Microbiol 74: 2314-2320.

González SS, Gallo L, Climent MD, Barrio E, Querol A. 2007. Enological characterization of natural hybrids from Saccharomyces cerevisiae and $S$. kudriavzevii. Int J Food Microbiol 116: 11-18.

Groth C, Hansen J, Piškur J. 1999. A natural chimeric yeast containing genetic material from three species. Int J Syst Bacteriol 49: 1933-1938.

Guindon S, Dufayard JF, Lefort V, Anisimova M, Hordijk W, Gascuel O. 2010. New algorithms and methods to estimate maximum-likelihood phylogenies: assessing the performance of PhyML 3.0. Syst Biol 59: 307-321.

Huson DH, Bryant D. 2006. Application of phylogenetic networks in evolutionary studies. Mol Biol Evol 23: 254-267.

Kellis M, Patterson N, Endrizzi M, Birren BW, Lander ES. 2003. Sequencing and comparison of yeast species to identify genes and regulatory elements. Nature 423: 241-254.

Kodama Y, Kielland-Brandt MC, Hansen J. 2005. Lager brewing yeast. In Comparative Genomics: using fungi as models, Sunnerhagen P, Piškur J (eds). SpringerVerlag, Berlin, Germany; 145-164.

Kurtzman CP. 2003. Phylogenetic circumscription of Saccharomyces, Kluyveromyces and other members of the Saccharomycetaceae, and the proposal of the new 
477

478

479

480

481

482

483

484

485

486

487

488

489

490

491

492

493

494

495

496

497

498

499

500

501

502

503

504

genera Lachancea, Nakaseomyces, Naumovia, Vanderwaltozyma and Zygotorulaspora. FEMS Yeast Res 4: 233-245.

Lee HY, Chou JY, Cheong L, Chang NH, Yang SY, Leu JY. 2008. Incompatibility of nuclear and mitochondrial genomes causes hybrid sterility between two yeast species. Cell 135: 1065-1073.

Lopandić K, Gangl H, Wallner E, Tscheik G, Leitner G, Querol A, Borth N, Breitenbach M, Prillinger H, Tiefenbrunner W. 2007. Genetically different wine yeasts isolated from Austrian vine-growing regions influence wine aroma differently and contain putative hybrids between Saccharomyces cerevisiae and Saccharomyces kudriavzevii. FEMS Yeast Res 7: 953-965.

Lopes CA, Barrio E, Querol A. 2010. Natural hybrids of Saccharomyces cerevisiae x Saccharomyces kudriavzevii share alleles with European wild populations of $S$. kudriavzevii. FEMS Yeast Res 10: 412-421.

Masneuf I, Hansen J, Groth C, Piškur J, Dubourdieu D. 1998. New hybrids between Saccharomyces sensu stricto yeast species found among wine and cider production strains. Appl Environ Microbio/ 64: 3887-3892.

Naumov GI, Masneuf I, Naumova ES, Aigle M, Dubourdieu D. 2000. Association of Saccharomyces bayanus var. uvarum with some French wines: genetic analysis of yeast populations. Res Microbiol 151: 683-691.

Naumov GI, Naumova ES, Antunovics Z, Sipiczki M. 2002. Saccharomyces bayanus var. uvarum in Tokaj wine-making of Slovakia and Hungary. Appl Microbiol Biotechnol 59: 727-730.

Naumov GI, Nguyen HV, Naumova ES, Michel A, Aigle M, Gaillardin C. 2001. Genetic identification of Saccharomyces bayanus var. uvarum, a cider-fermenting yeast. Int J Food Microbio/ 65: 163-171.

Naumova ES, Naumov GI, Masneuf-Pomarède I, Aigle M, Dubourdieu D. 2005. Molecular genetic study of introgression between Saccharomyces bayanus and S. cerevisiae. Yeast 22: 1099-1115. 
505 Orlić S, Arroyo-López FN, Huic-Babić K, Lucilla I, Querol A, Barrio E. 2010. A

506 comparative study of the wine fermentation performance of Saccharomyces

507 paradoxus under different nitrogen concentrations and glucose/fructose ratios. $J$

$508 \quad$ Appl Microbiol 108: 73-80.

509 Posada D. 2003. Inferring Evolutionary Relationships: Using Modeltest and PAUP* to

510 select a model of nucleotide substitution. In Current Protocols in Bioinformatics ,

511 Baxevanis AD, Page RDM, Petsko GA, Stein LD, Stormo GD (eds). John Wiley \&

$512 \quad$ Sons, 6.5.1-6.5.14.

513 Posada D. 2008. jModelTest: phylogenetic model averaging. Mol Biol Evol 25: 1253-

$514 \quad 1256$.

515 Querol A, Barrio E, Huerta T, Ramón D. 1992. Molecular monitoring of wine

516 fermentations conducted by active dry yeast strains. Appl Environ Microbio/ 58:

$517 \quad 2948-2953$.

518 Querol A, Fernández-Espinar MT, del Olmo M, Barrio E. 2003. Adaptative evolution of 519 wine yeast. Int J Food Microbiol 86: 3-10.

520 Querol, A. and U. Bond. 2009. The complex and dynamic genomes of industrial yeasts. $521 \quad$ FEMS Microbiol. Lett. 9999:

522 Redzepović S, Orlić S, Sikora S, Majdak A, Pretorius IS. 2002. Identification and 523 characterization of Saccharomyces cerevisiae and Saccharomyces paradoxus $524 \quad$ strains isolated from Croatian vineyards. Lett Appl Microbio/ 35: 305-310.

525 Rementería A, Rodríguez JA, Cadaval A, Amenábar R, Muguruza JR, Hernando FL, 526 Sevilla MJ. 2003. Yeast associated with spontaneous fermentations of white wines from the "Txakoli de Bizkaia" region (Basque Country, North Spain). Int J

529 Sampaio JP, Gonçalves P. 2008. Natural populations of Saccharomyces kudriavzevii in $530 \quad$ Portugal are associated with oak bark and sympatric with S. cerevisiae and $S$. $531 \quad$ paradoxus. Appl Environ Microbiol 74: 2144-2152. 
532 Schütz M, Gafner J. 1994. Dynamics of the yeast strain population during spontaneous

533 alcoholic fermentation determined by CHEF gel electrophoresis. Lett Appl

$534 \quad$ Microbiol 19: 253-257.

535 Tamura K, Dudley J, Nei M, Kumar S. 2007. MEGA4: Molecular evolutionary genetics

$536 \quad$ analysis (MEGA) software version 4.0. Mol Biol Evol 24: 1596-1599.

537 Torriani S, Zapparoli G, Suzzi G. 1999. Genetic and phenotypic diversity of

538 Saccharomyces sensu stricto strains isolated from Amarone wine. Antonie van

$539 \quad$ Leeuwenhoek 75: 207-215.

540 Vaughan-Martini A, Martini A. 2011. Saccharomyces Meyen ex Reess (1870). In The

541 yeasts: a taxonomic study. 5th ed., Kurtzman CP, Fell JW, Boekhout T (eds).

$542 \quad$ Elsevier, London; 733-746.

543 Wang SA, Bai FY. 2008. Saccharomyces arboricolus sp. nov., a yeast species from $544 \quad$ tree bark. Int J Syst Evol Microbiol 58: 510-514. 
548 Figure 1. Phylogenetic tree obtained with partial sequences of the nuclear MET6 gene from hybrid strains and reference strains of Saccharomyces. The

550 new hybrids are indicated in bold gray characters. Hybrid strains contain one,

551 two or three different MET6 alleles named C (S. cerevisiae), B ( $S$. bayanus var.

552 uvarum) or K (S. kudriavzevii) according to the closest parental relative.

553 Numbers at the nodes correspond to bootstrap values based on 1000 pseudo-

554 replicates. The scale is given in nucleotide substitutions per site.

556 Figure 2. RFLPs analysis of 35 nuclear genes from double hybrids. Each

557 square corresponds to a copy of each gene region according to its chromosome

558 location, indicated on the left map. Alleles of $S$. cerevisiae are indicated as

559 white squares and S. kudriavzevii alleles are represented as black squares.

561 Figure 3. RFLPs of 35 nuclear genes from triple hybrids. Each square

562 corresponds to a copy of each gene region according to its chromosome

563 location, indicated on the left map. Alleles of $S$. cerevisiae are indicated as

564 white squares, S. kudriavzevii alleles are represented as black squares and $S$.

565 bayanus alleles are depicted in grey squares. Squares filled with two colors

566 indicate that the presence of any of these alleles is possible. Gene orders are

567 the same for $S$. cerevisiae and S. kudriavzevii because their genomes are

568 colineal, however, gene orders differ for S. bayanus var. uvarum because this

569 species exhibits a series of reciprocal translocations as depicted. 
571 Figure 4. Phylogenetic Neighbor-net network obtained with partial sequences of

572 the mitochondrial COX2 gene from hybrid strains and reference

573 Saccharomyces strains. The new hybrids are indicated in bold gray characters.

574 The different COX2 sequence haplotypes are named by the initial of the species

575 name of the closest parental (C, for S. cerevisiae; and K, for S. kudriavzevii)

576 followed by a number, according to González et al. (2008). The new COX2

577 haplotypes described in the present study are indicated in italics. Strains

578 sharing the same haplotype are given at the left.

579 
Table 1. List of strains used in this study. Double hybrids correspond to $S$. cerevisiae $x$. kudriavzevii hybrids and triple hybrids to $S$. bayanus x S. cerevisiae x S. kudriavzevii hybrids. Accession numbers of new gene sequences are indicated.

\begin{tabular}{|c|c|c|c|c|c|}
\hline Strain type & $\begin{array}{l}\text { Strain } \\
\text { reference }\end{array}$ & Isolation source & COX2 & MET6-C & MET6-K \\
\hline \multirow[t]{10}{*}{ Double hybrids } & $\mathrm{AMH}$ & Commercial strain, Pinot noir wine, Assmanshausen, Germany & HQ414035 & HQ414054 & \\
\hline & HA1835 & Weißer Burgunder (Pinot blanc) grapes, Perchtoldsdorf, Austria & HQ414039 & HQ414049 & HQ414059 \\
\hline & HA1837 & Weißer Burgunder grapes, Perchtoldsdorf, Austria & HQ414040 & HQ414050 & HQ414060 \\
\hline & HA1841 & Weißer Burgunder grapes, Perchtoldsdorf, Austria & HQ414041 & HQ414051 & \\
\hline & HA1842 & Weißer Burgunder grapes, Perchtoldsdorf, Austria & HQ414042 & HQ414052 & HQ414061 \\
\hline & IF6 & Brewer's yeast dietary supplement, Barcelona, Spain & HQ414034 & HQ414057 & HQ414072 \\
\hline & MR25 & Human respiratory tract isolate, Barcelona, Spain & HQ414033 & HQ414058 & HQ414065 \\
\hline & PB7 & Pietro Picudo wine, Los Oteros Winery, León, Spain & HQ414036 & HQ414056 & HQ414064 \\
\hline & SOY3 & Graševina (Welschriesling) must fermentation, Daruvar, Croatia & HQ414032 & HQ414055 & HQ414063 \\
\hline & VIN7 & Commercial strain of unknown origin, Anchor, South Africa & HQ414031 & HQ414053 & HQ414062 \\
\hline \multirow[t]{2}{*}{ Triple hybrids } & CBS 2834 & Wine, Wädenswil, Switzerland & & & \\
\hline & CID1 & Home-made cider, Brittany, France & & & \\
\hline \multirow[t]{2}{*}{ S. kudriavzevii } & ZP542 & Oak bark, Adagoi, Portugal & HQ414038 & & \\
\hline & ZP591 & Oak bark, Castelo de Vide, Portugal & HQ414037 & & \\
\hline
\end{tabular}


Table 2. Comparison of COX2 haplotype sequences from hybrid and type and reference strains of Saccharomyces species. A dot indicates nucleotides identical to that from the type strain of $S$. cerevisiae CECT $1942^{\top}$. COX2 regions in hybrids that exhibit a higher similarity to $S$. cerevisiae, $S$. kudriavzevii and $S$. paradoxus COX2 sequences are indicated in squared white, black and grey backgrounds, respectively.

\begin{tabular}{|c|c|c|c|}
\hline \multirow[b]{2}{*}{ Species } & \multirow[b]{2}{*}{ Strains } & \multirow[b]{2}{*}{$\begin{array}{l}\text { COX2 } \\
\text { haplotype }\end{array}$} & COX2 variable nucleotide positions (in vertical) \\
\hline & & & $\begin{array}{r}1111111123333333444444455555555555555555555555555 \\
446790233355750127999233568800111111222222333344455566 \\
064342404647534380147403734728014789034569258901403658 \\
\end{array}$ \\
\hline \multirow{9}{*}{$\begin{array}{l}\text { S. cerevisiae } \\
\text { Hybrids }\end{array}$} & CECT1942 & $\mathrm{C} 1$ & ATTAATTTATTTTATATTCTATTATTTTACTCTAGCATTCTGGTGACATATGGC \\
\hline & $\mathrm{AMH}$ & $\mathrm{C} 2$ & 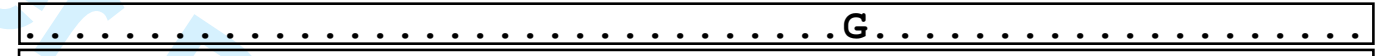 \\
\hline & IF6 & C3 & 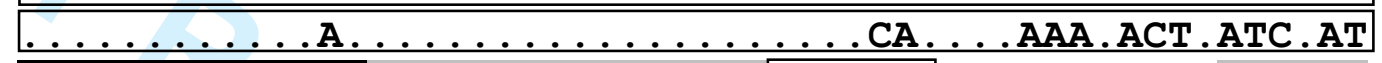 \\
\hline & CID1 & K5 & 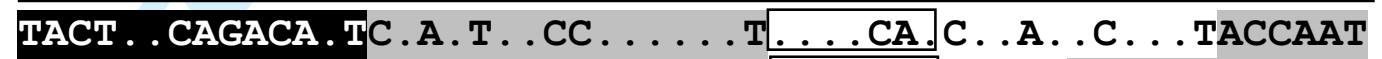 \\
\hline & PB7 & K10 & 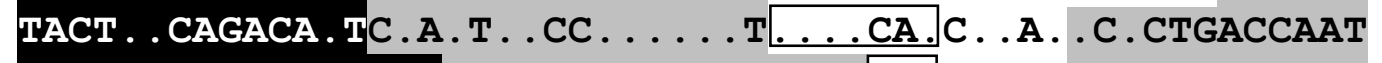 \\
\hline & MR25 \& brewing & K6 & 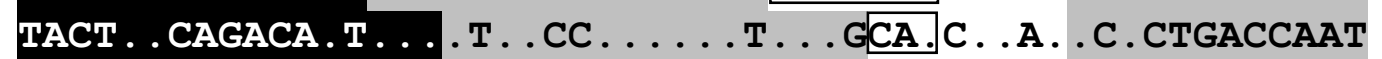 \\
\hline & Swiss \& 11003-4 & $\mathrm{K} 2$ & TACT. CAGACA. T...A.AT.CTAAAAG .AT.T. TCAG.A. . . . . . A. \\
\hline & W46 & K3 & TACT . . CAGACA . T . . A . AT . CTAAAAG . AT . T . TCAG . A. . . . . . . . A . \\
\hline & HAs, SOY3, VIN7 & K4 & TACT . . CAGACA . T . . A . AT . CTAAAAG . AT . T . TCAG . A. . A. . . . . . A . \\
\hline \multirow[t]{3}{*}{ S. kudriavzevii } & IFO1802 & K1 & TACT . . CAGACA . TC . A . AT . CT . AAAG . ATCT . TCAG . . . . . . . . A . \\
\hline & ZP542 & K8 & 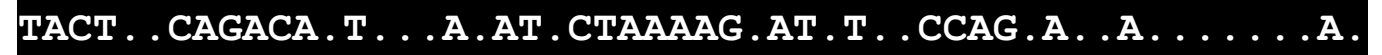 \\
\hline & ZP591 & K9 & 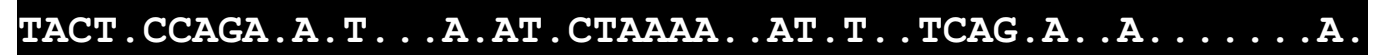 \\
\hline S. paradoxus & CECT1939 19 & $\mathrm{~K} 2$ & $\ldots \ldots \ldots \ldots$. . . T.CC .... . .G. . CAG.A.C.СTGACCAAT \\
\hline S. mikatae & IFO1815 & $\mathrm{K} 2$ & 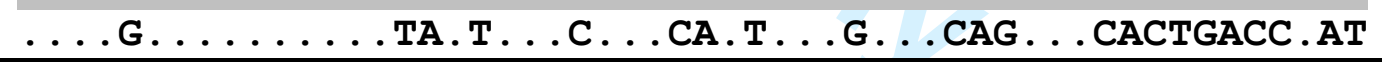 \\
\hline
\end{tabular}


Figure 1. Phylogenetic tree obtained with partial sequences of the nuclear MET6 gene from hybrid strains and reference strains of Saccharomyces. The new hybrids are indicated in bold gray characters. Hybrid strains contain one, two or three different MET6 alleles named C (S. cerevisiae), B (S. bayanus var. uvarum) or K (S. kudriavzevii) according to the closest parental relative. Numbers at the nodes correspond to bootstrap values based on 1000 pseudo-replicates. The scale is given in nucleotide substitutions per site. $119 \times 175 \mathrm{~mm}(600 \times 600 \mathrm{DPI})$ 
Figure 2. RFLPs analysis of 35 nuclear genes from double hybrids. Each square corresponds to a copy of each gene region according to its chromosome location, indicated on the left map. Alleles of S. cerevisiae are indicated as white squares and S. kudriavzevii alleles are represented as black squares.

$115 \times 86 \mathrm{~mm}(600 \times 600 \mathrm{DPI})$ 
Figure 3. RFLPs of 35 nuclear genes from triple hybrids. Each square corresponds to a copy of each gene region according to its chromosome location, indicated on the left map. Alleles of $S$. cerevisiae are indicated as white squares, S. kudriavzevii alleles are represented as black squares and $S$. bayanus var. uvarum alleles are depicted in grey squares. Squares filled with two colors indicate that the presence of any of these alleles is possible. Gene orders are the same for $S$. cerevisiae and S. kudriavzevii because their genomes are colineal, however, gene orders differ for $S$. bayanus var. uvarum because this species exhibits a series of reciprocal translocations as depicted. $160 \times 232 \mathrm{~mm}(600 \times 600 \mathrm{DPI})$ 
Figure 4. Phylogenetic Neighbor-net network obtained with partial sequences of the mitochondrial COX2 gene from hybrid strains and reference Saccharomyces strains. The new hybrids are indicated in bold gray characters. The different COX2 sequence haplotypes are named by the initial of the species name of the closest parental ( $C$, for S. cerevisiae; and K, for S. kudriavzevii) followed by a number, according to González et al. (2008). The new COX2 haplotypes described in the present study are indicated in italics. Strains sharing the same haplotype are given at the left. $115 \times 86 \mathrm{~mm}(600 \times 600$ DPI $)$ 
Table S1. Conformation of the $S$. cerevisiae $x$ S. kudriavzevii hybrids for each gene region according to the composite restriction patterns exhibited. For a description of the composite restriction patterns, see Gonzalez et al. (2008); Lopes et al. (2010) and Table S2. C: S. cerevisiae alleles, K: S. kudriavzevii alleles, B: S. bayanus var. uvarum alleles

\begin{tabular}{|c|c|c|c|c|c|c|c|c|c|c|c|c|c|}
\hline \multirow{2}{*}{$\begin{array}{l}\text { Chromo } \\
\text { some }\end{array}$} & \multirow[b]{2}{*}{ Gene } & \multicolumn{10}{|c|}{ Doble hybrids } & \multicolumn{2}{|c|}{ Triple hybrids } \\
\hline & & PB7 & 1835 & 1842 & 1837 & 1841 & SOY3 & AMH & Vin7 & IF6 & MR25 & CBS 2834 & CID1 \\
\hline \multirow[t]{2}{*}{$\bar{T}$} & CYC3 & C1K1 & C1K1 & $\mathrm{C} 1 \mathrm{~K} 1$ & $\mathrm{C} 1 \mathrm{~K} 1$ & $\mathrm{C} 1 \mathrm{~K} 1$ & $\mathrm{C} 1 \mathrm{~K} 1$ & $\mathrm{C} 1$ & C1K1 & $\mathrm{C} 1$ & $\mathrm{C} 1$ & C1B1 & $\mathrm{C} 1 \mathrm{~B} 1 \mathrm{~K} 1$ \\
\hline & BUD14 & C1K1 & $\mathrm{C} 1 \mathrm{~K} 1$ & $\mathrm{C} 1 \mathrm{~K} 1$ & $\mathrm{C} 1 \mathrm{~K} 1$ & $\mathrm{C} 1 \mathrm{~K} 1$ & $\mathrm{C} 1 \mathrm{~K} 1$ & $\mathrm{C} 1$ & C1K1 & C1 & $\mathrm{C} 1$ & C1 & C1B1K1 \\
\hline \multirow[t]{3}{*}{ II } & PKC1 & C1K1 & C1K1 & $\mathrm{C} 1 \mathrm{~K} 1$ & C1K1 & C1K1 & $\mathrm{C} 1 \mathrm{~K} 1$ & $\mathrm{C} 1$ & $\mathrm{C} 1 \mathrm{~K} 1$ & C1K1 & C1K1 & $\mathrm{C} 1 \mathrm{~K} 1$ & C1B1 \\
\hline & OPY1 & C1K1 & C1K1 & $\mathrm{C} 1 \mathrm{~K} 1$ & $\mathrm{C} 1 \mathrm{~K} 1$ & C1K1 & $\mathrm{C} 1 \mathrm{~K} 1$ & C1 & C1K1 & C1K1 & C1K1 & C1B1 & C1B1 \\
\hline & APM3 & C1K2 & C1K2 & $\mathrm{C} 1 \mathrm{~K} 2$ & $\mathrm{C} 1 \mathrm{~K} 2$ & $\mathrm{C} 1 \mathrm{~K} 2$ & $\mathrm{C} 1 \mathrm{~K} 2$ & $\mathrm{C} 1$ & $\mathrm{C} 1 \mathrm{~K} 2$ & C1K2 & C1K1 & C1B1K2 & C1B1K1 \\
\hline \multirow[t]{2}{*}{ III } & MRC1 & C1K1 & C1K1 & $\mathrm{C} 1 \mathrm{~K} 1$ & $\mathrm{C} 1 \mathrm{~K} 1$ & C1K1 & $\mathrm{C} 1 \mathrm{~K} 1$ & C1 & C1 & $\mathrm{C} 1$ & $\mathrm{C} 1 \mathrm{~K} 1$ & C1B1K1 & $\mathrm{C} 1 \mathrm{~B} 1 \mathrm{~K} 1$ \\
\hline & KIN82 & C1K1 & C1K1 & $\mathrm{C} 1 \mathrm{~K} 1$ & $\mathrm{C} 1 \mathrm{~K} 1$ & C1K1 & $\mathrm{C} 1 \mathrm{~K} 2$ & C1 & $\mathrm{C} 1$ & C1 & $\mathrm{C} 1 \mathrm{~K} 1$ & C1B1K1 & C1B1K1 \\
\hline \multirow[t]{3}{*}{ IV } & UGA3 & C1K1 & C1K1 & C1K1 & $\mathrm{C} 1 \mathrm{~K} 1$ & C1K1 & $\mathrm{C} 1 \mathrm{~K} 1$ & C1K1 & C1K1 & C1K1 & C1K1 & C1B1 & C1B1 \\
\hline & RPN4 & C1K1 & $\mathrm{C} 1 \mathrm{~K} 1$ & $\mathrm{C} 1 \mathrm{~K} 1$ & C1K1 & C1K1 & $\mathrm{C} 1 \mathrm{~K} 1$ & $\mathrm{C} 1$ & C1K1 & C1K1 & $\mathrm{C} 1 \mathrm{~K} 1$ & C1B1K1 & $\mathrm{C} 1 \mathrm{~B} 1 \mathrm{~K} 1$ \\
\hline & EUG1 & C1K2 & C1K2 & $\mathrm{C} 1 \mathrm{~K} 2$ & $\mathrm{C} 1 \mathrm{~K} 2$ & $\mathrm{C} 1 \mathrm{~K} 2$ & $\mathrm{C} 1 \mathrm{~K} 2$ & C1 & $\mathrm{C} 1 \mathrm{~K} 2$ & C1K2 & $\mathrm{C} 1 \mathrm{~K} 2$ & C1B1 & C1B1K1 \\
\hline \multirow[t]{2}{*}{ V } & NPR2 & C1K1 & C1K1 & C1K1 & C1K1 & C1 & C1K1 & C1 & C1K1 & C1 & C1K1 & C1B1K1 & C1B1K1 \\
\hline & MET6 & C1K1 & C1K1 & $\mathrm{C} 1 \mathrm{~K} 1$ & $\mathrm{C} 1 \mathrm{~K} 1$ & $\mathrm{C} 1$ & C1K1 & $\mathrm{C} 1$ & C1K1 & $\mathrm{C} 1$ & $\mathrm{C} 1 \mathrm{~K} 1$ & C1B1K1 & C1B1K1 \\
\hline \multirow[t]{2}{*}{ VI } & EPL1 & C1K1 & C1K1 & $\mathrm{C} 1 \mathrm{~K} 1$ & C1K1 & C1K1 & $\mathrm{C} 1 \mathrm{~K} 2$ & $\mathrm{C} 1 \mathrm{~K} 1$ & C1K1 & $\mathrm{C} 1$ & C1K1 & $\mathrm{K} 1$ & C1B1K1 \\
\hline & GSY1 & C1K1 & C1K1 & C1K1 & C1K1 & C1K1 & $\mathrm{C} 1 \mathrm{~K} 1$ & C1K1 & C1K1 & C1 & C1K1 & B1K1 & $\mathrm{C} 1 \mathrm{~B} 1 \mathrm{~K} 1$ \\
\hline \multirow[t]{2}{*}{ VII } & GCN1 & C1K1 & C1K1 & $\mathrm{C} 1 \mathrm{~K} 1$ & C1K1 & C1K1 & $\mathrm{C} 1 \mathrm{~K} 1$ & C1K1 & $\mathrm{C} 1 \mathrm{~K} 1$ & C1K1 & C1K1 & C1B1K1 & C1B1K1 \\
\hline & KEL2 & C1K1 & C1K1 & $\mathrm{C} 1 \mathrm{~K} 1$ & $\mathrm{C} 1 \mathrm{~K} 1$ & C1K1 & $\mathrm{C} 1 \mathrm{~K} 1$ & $\mathrm{C} 1$ & $\mathrm{C} 1$ & $\mathrm{C} 1$ & $\mathrm{C} 1$ & C1B1K1 & C1B1K1 \\
\hline \multirow[t]{2}{*}{ VIII } & CBP2 & C1K1 & C1K1 & $\mathrm{C} 1 \mathrm{~K} 1$ & C1K1 & C1K1 & $\mathrm{C} 1 \mathrm{~K} 1$ & C1 & C1K1 & C1K1 & C1K1 & C1B1 & $\mathrm{C} 1 \mathrm{~B} 1 \mathrm{~K} 1$ \\
\hline & MNL1 & C1K1 & C1K1 & $\mathrm{C} 1 \mathrm{~K} 1$ & C1K1 & C1K1 & $\mathrm{C} 1 \mathrm{~K} 1$ & C1 & C1K1 & C1K1 & $\mathrm{C} 1 \mathrm{~K} 1$ & C1B1 & C1B1K1 \\
\hline IX & UBP7 & C1K1 & $\mathrm{C} 1 \mathrm{~K} 1$ & $\mathrm{C} 1 \mathrm{~K} 1$ & $\mathrm{C} 1 \mathrm{~K} 1$ & C1K1 & C1K1 & C1K1 & C1K1 & C1 & C1 & C1B1K1 & B1K1 \\
\hline
\end{tabular}




\begin{tabular}{|c|c|c|c|c|c|c|c|c|c|c|c|c|c|}
\hline & $D A L 1$ & C1K1 & C1K1 & C1K1 & C1K1 & $\mathrm{C} 1 \mathrm{~K} 1$ & C1K1 & C1K1 & C1K1 & C1K1 & C1K1 & C1B1K1 & C1B1 \\
\hline \multirow[t]{3}{*}{$X$} & PEX2 & C1K1 & C1K1 & C1K1 & C1K1 & $\mathrm{C} 1 \mathrm{~K} 1$ & $\mathrm{C} 1 \mathrm{~K} 1$ & $\mathrm{C} 1$ & $\mathrm{C} 1 \mathrm{~K} 1$ & $\mathrm{C} 1$ & $\mathrm{C} 2$ & C1B1K1 & $\mathrm{B} 2 \mathrm{~K} 1$ \\
\hline & CYR1 & $\mathrm{C} 1 \mathrm{~K} 2$ & $\mathrm{C} 1 \mathrm{~K} 2$ & $\mathrm{C} 1 \mathrm{~K} 2$ & $\mathrm{C} 1 \mathrm{~K} 2$ & $\mathrm{C} 1 \mathrm{~K} 2$ & C1K2 & $\mathrm{C} 1$ & $\mathrm{C} 1 \mathrm{~K} 2$ & $\mathrm{C} 1 \mathrm{~K} 1$ & C1K1 & C1B1K2 & C1B1K2 \\
\hline & DAL5 & C1K1 & C1K1 & C1K1 & C1K1 & $\mathrm{C} 1 \mathrm{~K} 1$ & $\mathrm{C} 1 \mathrm{~K} 1$ & $\mathrm{C} 1$ & C1K1 & C1K1 & C1K1 & C1B1 & C1B1K1 \\
\hline \multirow[t]{2}{*}{ XI } & $C B T 1$ & C1 & C1K2 & C1K2 & C1K2 & C1K2 & C1K2 & $\mathrm{C} 1$ & C1K2 & C1K2 & C1K2 & C1B1K2 & C1B1 \\
\hline & BAS1 & C1K2 & C1K2 & C1K2 & C1K2 & C1K2 & C1K2 & $\mathrm{C} 1$ & C1K2 & C2K3 & CK2 & C1B1K2 & C1B1 \\
\hline \multirow[t]{2}{*}{ XII } & PPR1 & $\mathrm{C} 1 \mathrm{~K} 1$ & $\mathrm{C} 1 \mathrm{~K} 1$ & $\mathrm{C} 1 \mathrm{~K} 1$ & $\mathrm{C} 1 \mathrm{~K} 1$ & $\mathrm{C} 1 \mathrm{~K} 1$ & $\mathrm{C} 1 \mathrm{~K} 1$ & $\mathrm{C} 1$ & C1K1 & $\mathrm{C} 1 \mathrm{~K} 1$ & $\mathrm{C} 1 \mathrm{~K} 1$ & C1B1 & C1B1K1 \\
\hline & MAG2 & C1K1 & $\mathrm{C} 1 \mathrm{~K} 1$ & C1K1 & C1K1 & $\mathrm{C} 1 \mathrm{~K} 1$ & C1K1 & $\mathrm{C} 1$ & $\mathrm{C} 1 \mathrm{~K} 1$ & C1 & $\mathrm{C} 1 \mathrm{~K} 1$ & B1 & $\mathrm{C} 1 \mathrm{~K} 1$ \\
\hline \multirow[t]{2}{*}{ XIII } & ORC1 & $\mathrm{C} 1 \mathrm{~K} 1$ & C1K1 & C1K1 & C1K1 & $\mathrm{C} 1 \mathrm{~K} 1$ & C1K1 & $\mathrm{C} 1 \mathrm{~K} 1$ & C1K1 & C1K1 & C1 & C1B1K1 & C1B1K1 \\
\hline & CAT8 & C1K1 & C1K1 & C1K1 & C1K1 & C1K1 & C1K1 & $\mathrm{C} 1 \mathrm{~K} 1$ & C1K1 & C1 & C1K1 & C1B1K1 & C1B1K1 \\
\hline \multirow[t]{2}{*}{ XIV } & EGT2 & C1K1 & C1K1 & $\mathrm{C} 1 \mathrm{~K} 1$ & $\mathrm{C} 1 \mathrm{~K} 1$ & $\mathrm{C} 1 \mathrm{~K} 1$ & $\mathrm{C} 1 \mathrm{~K} 1$ & $\mathrm{C} 1$ & C1K1 & C1K1 & $\mathrm{C} 1 \mathrm{~K} 1$ & C1B1 & C1B1K1 \\
\hline & BRE5 & $\mathrm{C} 1 \mathrm{~K} 1$ & $\mathrm{C} 1 \mathrm{~K} 1$ & $\mathrm{C} 1 \mathrm{~K} 1$ & $\mathrm{C} 1 \mathrm{~K} 1$ & $\mathrm{C} 1 \mathrm{~K} 1$ & C1K1 & $\mathrm{C} 1$ & C1K1 & $\mathrm{C} 1 \mathrm{~K} 1$ & $\mathrm{C} 1$ & C1B1K1 & $\mathrm{B} 2 \mathrm{~K} 1$ \\
\hline \multirow[t]{2}{*}{$\mathbf{X V}$} & $R R I 2$ & $\mathrm{C} 1 \mathrm{~K} 1$ & C1K1 & C1K1 & C1K1 & $\mathrm{C} 1 \mathrm{~K} 1$ & $\mathrm{C} 1 \mathrm{~K} 1$ & C1 & $\mathrm{C} 1 \mathrm{~K} 1$ & C1K1 & $\mathrm{C} 1 \mathrm{~K} 1$ & C1B1K1 & $\mathrm{C} 1 \mathrm{~B} 1 \mathrm{~K} 1$ \\
\hline & ATF1 & C1K1 & C1K1 & C1K1 & C1K1 & $\mathrm{C} 1 \mathrm{~K} 1$ & C1K1 & $\mathrm{C} 1 \mathrm{~K} 1$ & C1K1 & C1K1 & C1K1 & $\mathrm{B} 1 \mathrm{~K} 1$ & C1B1K1 \\
\hline \multirow[t]{2}{*}{ XVI } & GAL4 & C1K1 & C1K1 & C1K1 & C1K1 & C1K1 & C1K1 & C1 & C1K1 & C1K1 & C1K1 & C1B1K1 & C1B1K1 \\
\hline & JIP5 & C1K1 & C1K1 & $\mathrm{C} 1 \mathrm{~K} 1$ & $\mathrm{C} 1 \mathrm{~K} 1$ & $\mathrm{C} 1 \mathrm{~K} 1$ & $\mathrm{C} 1 \mathrm{~K} 1$ & $\mathrm{C} 1$ & $\mathrm{C} 1 \mathrm{~K} 1$ & $\mathrm{C} 1 \mathrm{~K} 1$ & C1K1 & C1B1K1 & C1B1K1 \\
\hline
\end{tabular}


Table S2. New restriction patterns found in S. cerevisiae $x$ S. kudriavzevii hybrids deriving from those described in González et al. (2008) and Lopes et al. (2010).

\begin{tabular}{clccc}
\hline Chromosome & Gene & Restriction enzyme & \multicolumn{2}{c}{ New patterns } \\
\hline X & PEX2 & Hae III & 33021012040 & B2 \\
XI & BAS1 & Hae III & 690380 & B2 \\
XI & BAS1 & Hae III & 485485110 & C2 \\
XI & BAS1 & Hae III & 700180140110 & K4 \\
\hline
\end{tabular}




\section{Reference List}

González SS, Barrio E, Querol A. 2008. Molecular characterization of new natural hybrids

between Saccharomyces cerevisiae and Saccharomyces kudriavzevii from brewing. Appl

Environ Microbiol 74: 2314-2320.

Lopes CA, Barrio E, Querol A. 2010. Natural hybrids of Saccharomyces cerevisiae x

Saccharomyces kudriavzevii share alleles with European wild populations of S. kudriavzevii.

FEMS Yeast Res 10: 412-421. 